\title{
IMPROVEMENT OF THE TECHNOLOGY OF WELDING HIGH-TEMPERATURE DIAPHRAGMS IN STEAM TURBINE FLOW SECTION*
}

\author{
A.K. TSARYUK ${ }^{1}$, V.Yu. SKULSKY ${ }^{1}$, M.A. NIMKO ${ }^{1}$, A.N. GUBSKY ${ }^{2}$, A.V. VAVILOV ${ }^{2}$ and A.G. KANTOR ${ }^{2}$ \\ ${ }^{1}$ E.O. Paton Electric Welding Institute, NASU \\ 11 Kazimir Malevich Str., 03680, Kiev, Ukraine. E-mail: office@paton.kiev.ua \\ ${ }^{2}$ Company «Turboatom» \\ 199 Moskovsky Ave., 61037, Kharkov, Ukraine. E-mail: office@turboatom.com.ua
}

\begin{abstract}
Special features and causes for operational damage in welded components of high-temperature diaphragms are considered. Comparative testing was performed of welding-technological properties of some commercially available coated electrode grades for welding heat-resistant steels of $\mathrm{Cr}-\mathrm{Mo}$ and $\mathrm{Cr}-\mathrm{Mo}-\mathrm{V}$ compositions. Implant procedure and welding of Tekken technological samples were used to assess the delayed fracture susceptibility of $15 \mathrm{Kh} 12 \mathrm{VNMF}+$ $15 \mathrm{Kh} 1 \mathrm{M} 1 \mathrm{FL}$ steel welded joints at application of selected electrodes. It is established that to ensure a high cold cracking resistance of these steel welded joints, it is necessary to apply preheating at $200-250{ }^{\circ} \mathrm{C}$. Proceeding from the data of measurement of metal hardness in welds and HAZ of welded joints and weld metal impact toughness, an optimum mode of heat treatment of $15 \mathrm{Kh} 12 \mathrm{VNMF}+15 \mathrm{Kh} 1 \mathrm{M} 1 \mathrm{FL}$ steel welded joints was determined. It is shown that a softening zone of lower hardness forms in the HAZ metal structure of $15 \mathrm{Kh} 12 \mathrm{VNMF}$ steel, in which the samples fail at testing for static tension at working temperature of $570{ }^{\circ} \mathrm{C} .8$ Ref., 4 Tables, 10 Figures.
\end{abstract}

Keywords : arc welding, heat-resistant steels, dissimilar steel welded joints, cold cracks, heat treatment

Characteristic features of components making up the turbine flow section are the impact of dynamic and vibrational forces on them in operation and high requirements to manufacturing accuracy. Combination of various steel grades in one component is extensively applied in these structures. At present, flow section structures in the welded form have become widely accepted in turbine construction practices.

Heat-resistant steels of pearlitic class of $15 \mathrm{Kh} 1 \mathrm{M} 1 \mathrm{~F}$ type are the usually applied materials for diaphragm body and rim in manufacture of high-temperature

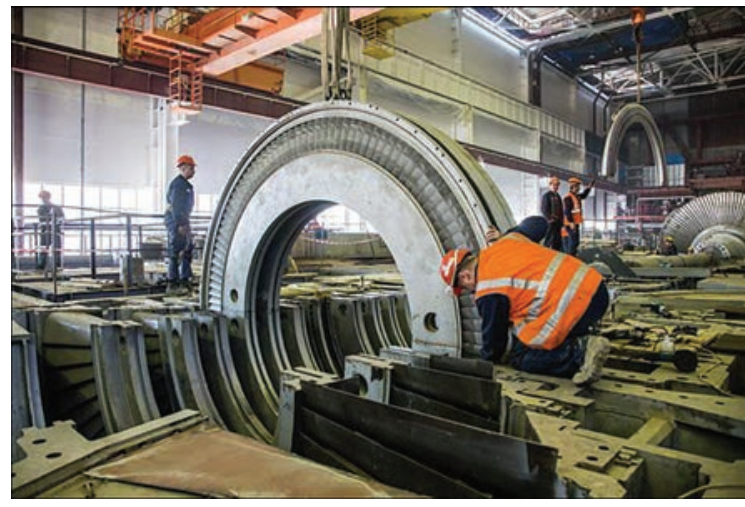

Figure 1. Control assembly of diaphragms in MPC body welded diaphragms for high (HPC) and medium pressure cylinders (MPC).

The vanes are made of high-temperature chromium steels of $15 \mathrm{Kh} 11 \mathrm{MF}, 15 \mathrm{Kh} 12 \mathrm{VNMF}$ (EI-802) or 18Kh11MFB type. Stainless chromium steel 12Kh13 is the most extensively applied for shrouds (shroud strip). In manufacture of high-temperature diaphragms these steels should be welded to each other in different combinations. Considering that, the above steels belong to different structural classes, their welding involves certain difficulties in terms of ensuring the required physical-mechanical and service properties of welded joints, as well as their reliable operation under creep conditions at working temperatures from 480 to $600{ }^{\circ} \mathrm{C}$. Therefore, the purpose of this work was optimization of the technology of welding parts from dissimilar steels in manufacture of high-temperature diaphragms to increase the reliability and life of steam turbine flow section.

The diaphragms pertain to the most mass welded components of turbine units. Stationary steam turbines can contain a considerable number of stages (up to 20) and the same number of diaphragms of different type size, respectively. The diaphragms are used to

\footnotetext{
${ }^{*}$ Based on materials of the work performed under purpose-oriented integrated program of the NAS of Ukraine «Problems of residual life and safe operation of structures, constructions and machines» (2013-2015).
} 

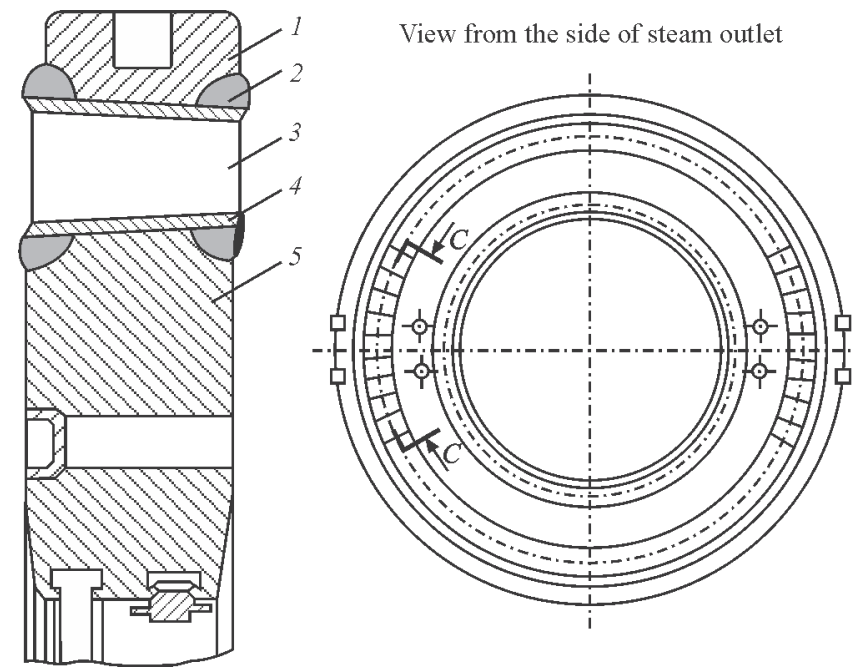

Developed section $C-C$

Figure 2. Typical structure of steam turbine welded diaphragm: 1 - rim; 2 - upper shroud strip; 3 - guide vanes; 4 - lower shroud strip; 5 - body

divide turbine cylinder into individual compartments. In the guide-vane assembly of the diaphragms the steam flow potential energy turns into kinetic energy. Moreover, flow direction is established. The guidevane assembly consists of guide vane grid, forming the nozzle channels.

Diaphragm is one of the most critical parts of the turbine. It has a horizontal joint and consists of two halves. One half is fixed in the lower, and the other -

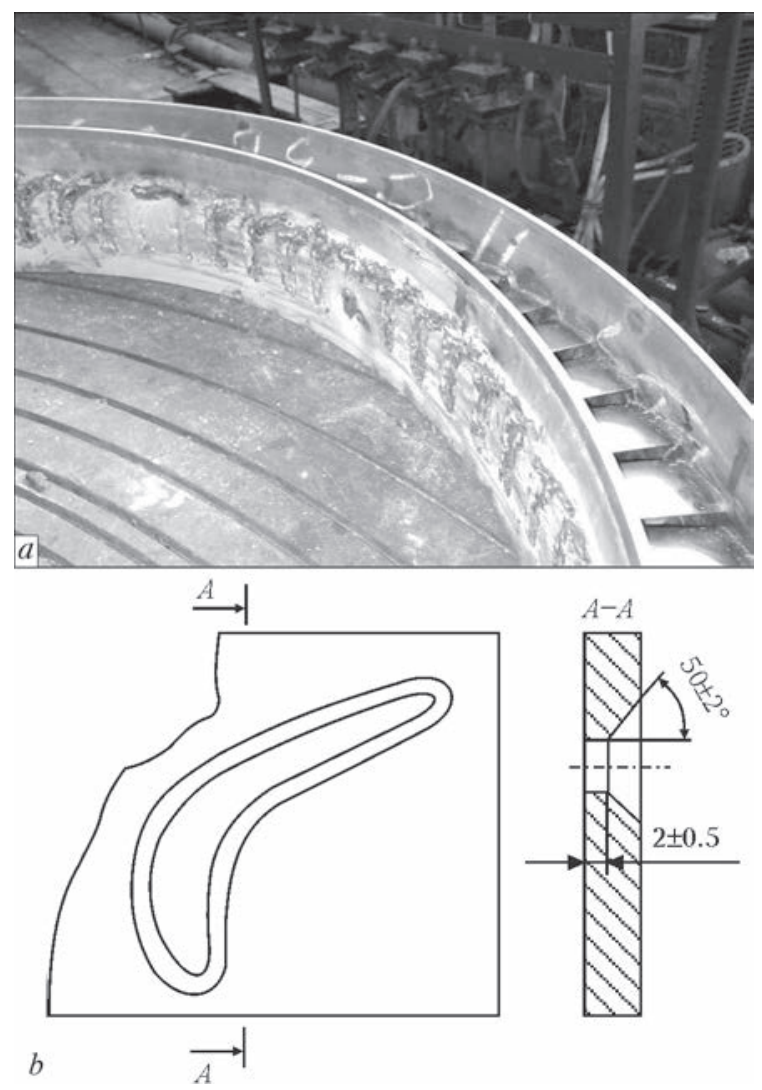

Figure 3. Welding of guide vane end faces to shroud strips by technological weld: $a$ - appearance of the grid after welding; $b$ - groove shape for vane welding around the contour of profile holes in shroud strip in the upper half of cylinder body (Figure 1). The diaphragms are inserted directly into the body bores or into special yokes, fixed on the body $[1,2]$.

Typical structure of steam turbine welded diaphragm (Figure 2) consists of the body, rim and guide-vane grid, including the inner and outer shroud strips with punched holes, into which the vanes are inserted. The shroud strips curved along a cylindri-
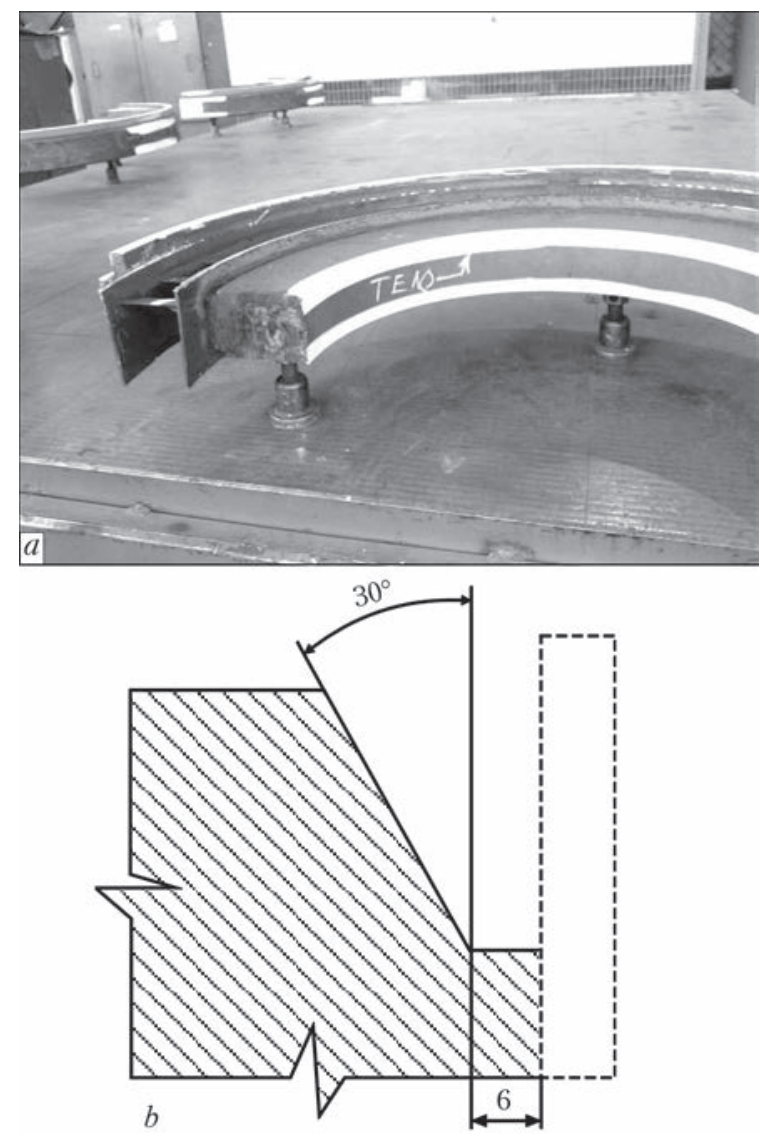

Figure 4. Assembly of diaphragm half for welding of load-carrying welds: $a$ - appearance of assembled diaphragm; $b$ - typical groove shape in the body (rim) for manual arc welding of load-carrying welds 
cal surface are usually made of $4-10 \mathrm{~mm}$ thick strip. When assembling the grid, the vanes are mounted in the shroud strip slots, inserting them for $2-3 \mathrm{~mm}$. To ensure a reliable connection of the vanes to the body and the shroud, their end faces are welded around the hole contour by a technological weld, flush with the shroud strip (Figure 3). Then, the vane grid, together with shroud, is welded by the main load-carrying welds to the diaphragm body and the rim (Figure 4). Typical groove shape for welding the main welds of the diaphragm is shown in Figure 4, $b$. These welds are the most stressed areas of welded diaphragms, as they join the shroud strips and vanes to the body and rim, and forces, applied to the vanes due to working medium pressure, are transmitted through them to diaphragm rim. Usually, the height of welds, connecting the grid with the body and rim, is equal to $0.2-0.3$ of profile width. Further increase of weld height is not rational, as it leads to excess deformation of the structure in welding.

As shown by calculations [3] and experimental results [4], stresses in the diaphragms are non-uniformly distributed and are the highest in the vanes and welds adjacent to the joint. These stresses decrease markedly at greater distance from the joint. Diaphragm testing to fracture [5] confirms that fracture usually starts from welds of near-the-joint vanes at the body, i.e. in the location that is the most stressed one, according to calculation. Requirements made to accu-
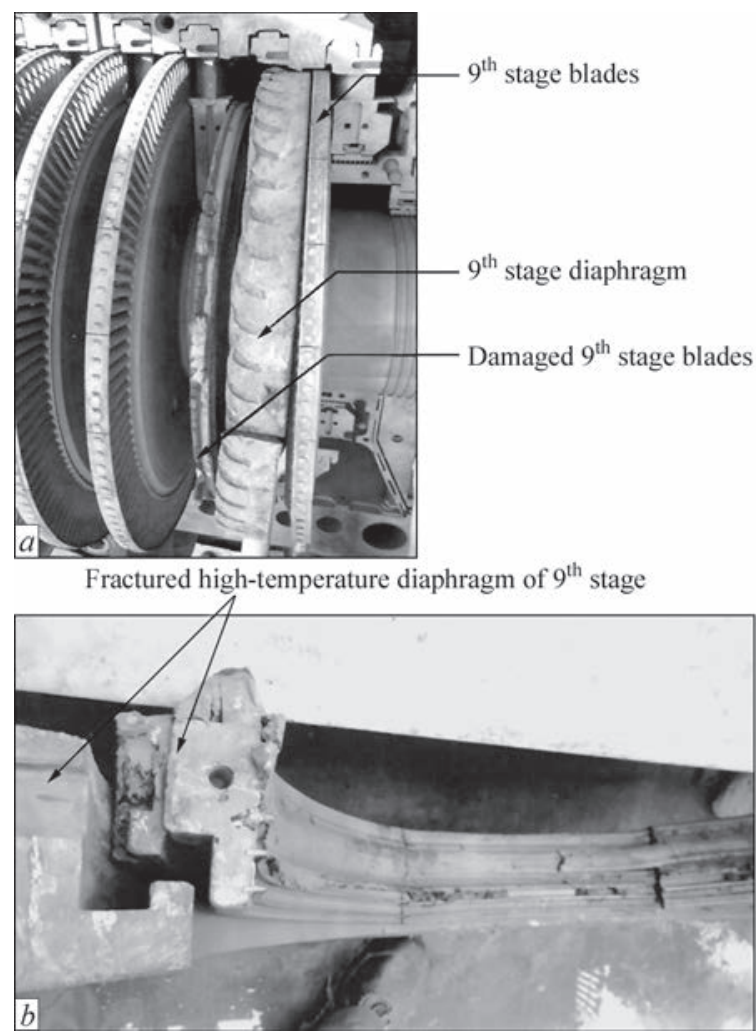

racy of diaphragm manufacture, specify the need to maintain the basic dimensions of the flow section with very close tolerances. Measures ensuring the required accuracy of structure geometry should be specially envisaged to meet the requirements made at all the stages of the technological process of manufacturing the diaphragms. These measures include assembly and welding of diaphragm components in special devices, providing the required accuracy of mounting the inserted parts, allowing for welding deformations when punching slots in shroud strips and application of additional ruggedness in welding, which reduces structure distortion.

Welding deformations are the main reason, causing deviation of diaphragm dimensions from the specified ones. Slot piercing in shroud strips and item machining are performed with sufficient accuracy and tolerances for these operations performance completely fit within the general tolerances for diaphragms. At the same time, welding deformations, as a rule, exceed the admissible ones by the structure operating conditions.

At long-term operation of steam turbines in TPP, emergency situations can develop in the flow section of HPC and MPC, associated with fracture of high-temperature diaphragms. Figure 5 shows the damage of such diaphragms and blades.

The main damage during long-term operation is found in welded joints of guide vanes with diaphragm

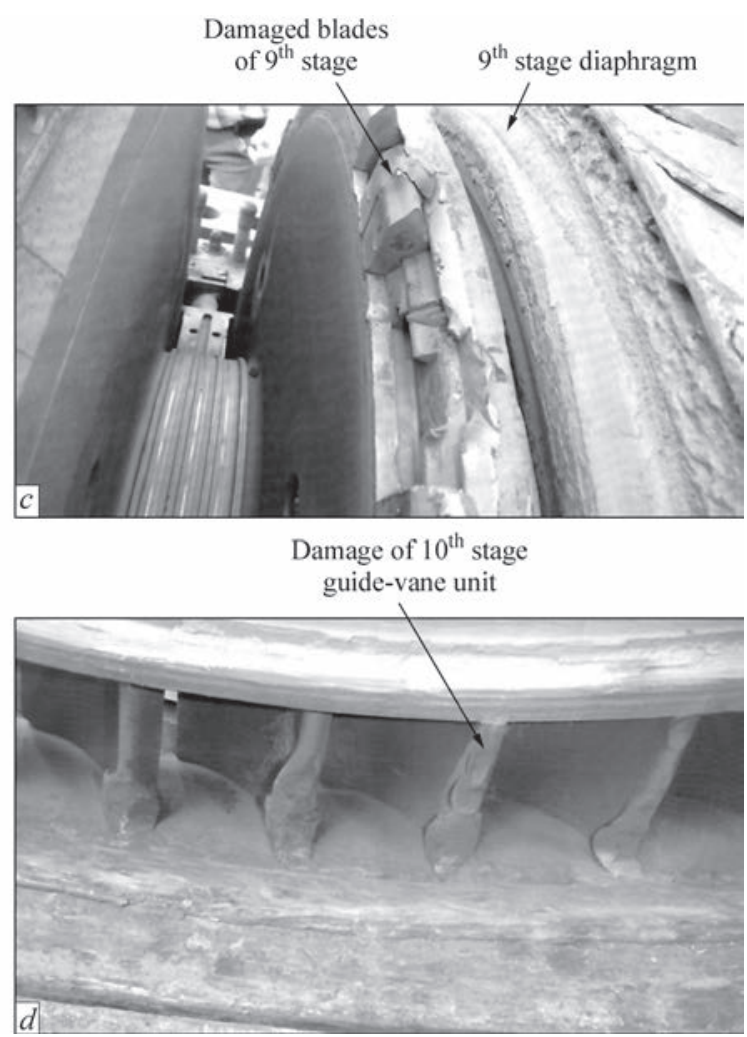

Figure 5. Damage of diaphragms and blades of K-160-130 turbine: $a-$ HPC; $b-$ HPC; $c-$ appearance of damage in HPC flow section; $d$ - cracking of guide-vane unit of HPC 
Table 1. Composition of metal deposited with coated electrodes for welding high-temperature diaphragms

\begin{tabular}{|c|c|c|c|c|c|c|c|c|}
\hline \multirow{2}{*}{ Electrode grade } & \multicolumn{7}{|c|}{ Mass fraction of elements, \% } \\
\cline { 2 - 10 } & $\mathrm{C}$ & $\mathrm{Mn}$ & $\mathrm{Si}$ & $\mathrm{Mo}$ & $\mathrm{Cr}$ & $\mathrm{V}$ & $\mathrm{S}$ & $\mathrm{P}$ \\
\hline TML-3U & $0.06-0.12$ & $0.50-0.90$ & $0.15-0.40$ & $0.40-0.70$ & $0.80-1.25$ & $0.15-0.30$ & $\leq 0.025$ & $\leq 0.030$ \\
\hline TsL-20 & $0.06-0.12$ & $0.60-0.90$ & $0.18-0.40$ & $0.40-0.70$ & $0.80-1.25$ & $0.12-0.30$ & $\leq 0.025$ & $\leq 0.030$ \\
\hline
\end{tabular}

body and rim. Fracture runs in the fusion zone of guide vane end face with weld metal. This zone is the most high-loaded and vulnerable portion of the diaphragm, and determines the serviceability of the diaphragm as a whole. The cause for damage and failure of guide-vane assemblies, apparently, is the influence of technological factors in diaphragm manufacture, as well as formation of stress-strain state in diaphragm structural components under working conditions of turbine operation.

To clarify the possible influence of technological factors in manufacture of welded high-temperature diaphragms, it is of interest to perform analysis of the process of diaphragm assembly, welding and heat treatment at Company «Turboatom» (Kharkov) [6].

Technological instructions on manufacture of welded diaphragms envisage performance of all regulated operations in strict compliance with the requirements of OST 108.021.04-78 [2], RTM 108.020.35-81 [7], as well as design documentation of «Turboatom» DB.

The following welding consumables are applied for welded high-temperature diaphragm components:

- EA-395/9 coated electrodes - for welding the guide vanes from 15Kh12VNMF (EI-802) or $15 \mathrm{Kh} 11 \mathrm{MFA}$ steel to shroud strip from $12 \mathrm{Kh} 13 \mathrm{steel}$;

- TML-3U coated electrodes - for welding the grid to diaphragm body and rim.

Fixing the guide vanes in shroud strip slots during assembly is performed with tack welds of $10-15 \mathrm{~mm}$ length. Vane welding around the contour is done in one pass. Welding is conducted simultaneously along the outer and inner shrouds, starting from the segment middle, 2-3 blades at a time, then from the joint side, etc. Grid welding is performed only in its horizontal position.

Application of EA-395/9 electrodes for assembly and welding of chromium steels in grid manufacture enables elimination of preheating and performance of postweld heat treatment (high tempering at $690{ }^{\circ} \mathrm{C}$ ). Assembly and welding are performed without preheating at reverse polarity direct current. Welding current was $60-80$ A for $3.0 \mathrm{~mm}$ electrode.

Uphill welding is performed by a short arc with narrow beads. Vane weld sections located vertically or inclined at not more than $15^{\circ}$ angle to the vertical can be welded in downhill direction.

Assembly of the diaphragm (grid joining to diaphragm body and rim) is performed in a special de- vice with TML-3U or TsL-20 electrodes using tack welds of 80 to $120 \mathrm{~mm}$ length with local preheating of tack location to $250-300{ }^{\circ} \mathrm{C}$.

Composition of metal deposited with these electrodes is given in Table 1.

Assembled diaphragm is sent on for welding. Diaphragm welding is performed with the same electrodes with preheating and concurrent heating to not lower than $300{ }^{\circ} \mathrm{C}$.

When welding the grid to diaphragm body and rim, groove filling should be started from the side of steam inlet. During welding, periodical tilting of the diaphragm through $180{ }^{\circ} \mathrm{C}$ should be performed. The number of tilting operations is determined by the technology of welding this diaphragm.

During welding of circular welds, their peening should be performed. Peening of the first and last layer is not applied. Figure 6 shows the sequence of groove filling. Groove filling is performed in sections of $250-350 \mathrm{~mm}$ length in the direction from the middle to the edges. Taking into account the diaphragm tilting, first a layer from the body side, then one from the rim side are welded and so on, continuously alternating layer bead deposition in welds joining the grid to the body and rim.

After welding the diaphragm, not letting it cool below $300{ }^{\circ} \mathrm{C}$, it is placed into the furnace, and tempering is performed at $710-720^{\circ} \mathrm{C}$. Heating to tempering temperature should be conducted at the rate of $50-60{ }^{\circ} \mathrm{C} / \mathrm{h}$. A pause between welding and heat treatment of up to $72 \mathrm{~h}$ is allowed under the condition of
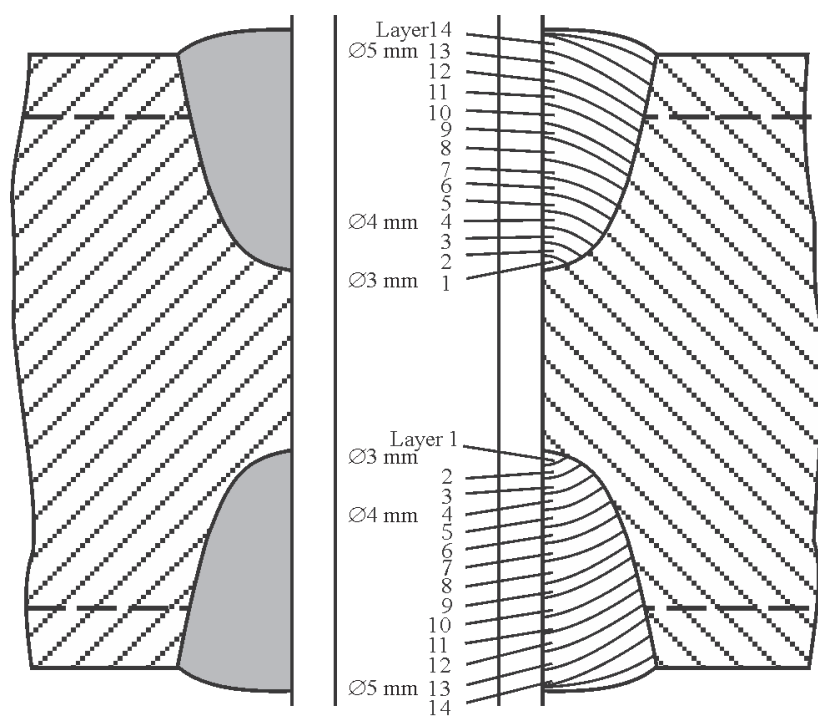

Figure 6. Sequence of filling the grooves of load-carrying welds 
Table 2. Composition of metal deposited with MTS-4 and Kupfer 3KC electrodes

\begin{tabular}{|c|c|c|c|c|c|c|c|c|c|c|c|c|c|c|}
\hline \multirow{2}{*}{ Electrode grade } & \multicolumn{14}{|c|}{ Composition, wt.\% } \\
\hline & $\mathrm{C}$ & $\mathrm{Si}$ & $\mathrm{Mn}$ & $\mathrm{Cr}$ & $\mathrm{Ni}$ & W & $\mathrm{V}$ & Mo & $\mathrm{Nb}$ & $\mathrm{Cu}$ & $P$ & $\mathrm{~S}$ & {$\left[\mathrm{~N}_{2}\right]$} & {$\left[\mathrm{O}_{2}\right]$} \\
\hline MTS-4 & 0.16 & 0.20 & 0.53 & 10.5 & 0.51 & 0.47 & 0.21 & 0.87 & 0.046 & $<0.1$ & 0.017 & 0.007 & 0.03 & 0.052 \\
\hline Kupfer 3KC & 0.12 & 0.35 & 0.91 & 1.38 & 0.07 & - & 0.25 & 1.0 & - & $<0.1$ & 0.021 & 0.012 & 0.03 & 0.048 \\
\hline
\end{tabular}

weldment soaking after welding for $5 \mathrm{~h}$ at preheating temperature and delayed cooling. Soaking at specified temperature is performed for $6-12 \mathrm{~h}$. Cooling is conducted at not more than $50{ }^{\circ} \mathrm{C} / \mathrm{h}$ rate to the temperature of $150{ }^{\circ} \mathrm{C}$.

Performed analysis of the causes for damage of high-temperature diaphragms (see Figure 5), as well as studying the currently applied technology of welding the guide-vane assembly and the load-carrying welds of the diaphragm shows that one of the determinant factors of fracture is the low level of load-carrying weld metal service properties (ultimate strength and yield limit). Coated electrodes of TML-3U or TsL20 type, applied for manual welding of load-carrying welds, cannot ensure the required service properties of welded joints of guide vanes from 15Kh11MFA steel with body and rim of diaphragm from $15 \mathrm{Kh} 1 \mathrm{M}$ 1FL steel. As to long-term strength values, the metal of weld, made with the above electrodes, is significantly inferior even to cast steel $15 \mathrm{Kh} 1 \mathrm{M} 1 \mathrm{FL}$ of the body and rim. This is indicative of the need to improve the currently available technology of welding the diaphragm joints. In view of the above, selection of advanced welding consumables and improvement of the technology of welding high-temperature diaphragms is an extremely important problem. The urgency of its solution rises in connection with the need to create new generation turbogenerators with high steam parameters (up to $600{ }^{\circ} \mathrm{C}$ temperature and 300 bar pressure).

A marketing search was first conducted to find coated electrodes for welding heat-resistant steels of $\mathrm{Cr}-\mathrm{Mo}$ and $\mathrm{Cr}-\mathrm{Mo}-\mathrm{V}$ composition, providing guaranteed long-term strength $\left(\sigma_{1 .}\right)$ of weld metal at $570{ }^{\circ} \mathrm{C}$ during $100,000 \mathrm{~h}$ at the level of $140-150 \mathrm{MPa}$ $\left(\sigma_{1 . t}\right.$ of $15 \mathrm{Kh} 1 \mathrm{M} 1 \mathrm{FL}$ steel at $570{ }^{\circ} \mathrm{C}$ for $100,000 \mathrm{~h}$ is equal to $100 \mathrm{MPa}$ ). Local electrodes, as well as electrodes of Boehler (Germany), ECAB (Sweden) and other foreign manufacturers were considered. Based on marketing search results, preference was given to the following electrodes manufactured by Boehler:

- Thermanit MTS-4 (basic coated chromium electrodes (up to $11 \% \mathrm{Cr}$ ) for welding steels, operating at up to $580^{\circ} \mathrm{C}$ temperatures);

- Phoenix SH Kupfer 3KC (basic coated $\mathrm{Cr}$ Mo-V electrodes for welding components operating at up to $600{ }^{\circ} \mathrm{C}$ temperatures).
Comparative studies of the above electrodes demonstrated somewhat better welding-technological properties at application of Phoenix SH Kupfer 3KC electrodes.

Main element content and gas content in the metal deposited with the above electrodes is given in Table 2 .

Content of diffusible hydrogen in the deposited metal was studied using alcohol sample [8]. Investigation results showed that diffusible hydrogen content in the deposited metal in welding with MTS-4 electrodes is at the level of $[\mathrm{H}]_{\text {dif }}=2.1-2.3$, and in welding with Kupfer $3 \mathrm{KC}$ electrodes $[\mathrm{H}]_{\text {dif }}=1.8-2.0 \mathrm{~cm}^{3} / 100 \mathrm{~g}$. In keeping with the data of [8], diffusible hydrogen level in the deposited metal should be lower than $5.0 \mathrm{~cm}^{3} / 100 \mathrm{~g}$, that corresponds to the requirements made of both the coated electrode grades.

Thus, the conducted comparative testing of welding-technological properties of coated electrodes for welding combined joints of heat-resistant steels of $\mathrm{Cr}-\mathrm{Mo}-\mathrm{V}$ composition and chromium steel with 11$12 \% \mathrm{Cr}$ showed that tested electrode grades MTS-4 and Kupfer $3 \mathrm{KC}$ are, in principle, suitable for making load-carrying welds of high-temperature diaphragms.

Delayed cracking susceptibility of welded joints of $15 \mathrm{Kh} 12 \mathrm{VNMFA}$ steel was assessed by testing by Implant procedure and by welding technological samples of Tekken type (GOST 26388-84) with application of selected electrodes. The criterion of delayed fracture resistance by Implant method is critical stress, above which test joints fail. Stress in the joint is calculated as the ratio of loading force to sample cross-section.

Results of testing by Implant method are given in Figure 7. It is seen that compared to welding without preheating, a significant increase of critical stresses is in place at preheating above $150{ }^{\circ} \mathrm{C}$. Maximum level of stresses in 15Kh12VNMFA steel joint is maintained at $T_{\mathrm{pr}} \sim 250^{\circ} \mathrm{C}$. The highest cracking resistance corresponds to this condition. Preheating to higher temperature under these experimental conditions did not give any advantage. Cracking resistance remained at approximately the same level, as in joints welded with $T_{\mathrm{pr}}=250^{\circ} \mathrm{C}$.

Results of Implant testing of 15Kh12VNMFA steel joints, made with Kupfer $3 \mathrm{KC}$ electrodes, are given in Figure $7, b$. The curve, separating the regions of crack presence and absence, consists of tentative values of critical stresses. 
Preheating up to $100{ }^{\circ} \mathrm{C}$ practically does not affect crack resistance - critical stresses remain on the same level as in welding without preheating. At preheating above $100{ }^{\circ} \mathrm{C}$, crack resistance rises markedly, that is indicative of the rationality of application of preheating at these temperatures. At application of $T_{\mathrm{pr}}=200-250^{\circ} \mathrm{C}$ delayed cracking resistance rises more intensively than at preheating in the range of $150-200{ }^{\circ} \mathrm{C}$. This is confirmed by a steeper rise of the curve in $200-250{ }^{\circ} \mathrm{C}$ section than in that for $150-200{ }^{\circ} \mathrm{C}$ (or greater angle $\alpha_{2}$ of inclination of the tangent to the curve in $200-250^{\circ} \mathrm{C}$ section than angle $\alpha_{1}$ in $150-200{ }^{\circ} \mathrm{C}$ section).

Derived testing results confirm that preheating in the range of $200-250{ }^{\circ} \mathrm{C}$ should be used to ensure a high delayed cracking resistance of 15Kh12VNMFA steel welded joints at application of Kupfer 3KC electrodes. Investigation of macrosections showed that the main type of deposited metal structure is high-tempered bainite, formed without pre-deformation (from cast metal) with coagulated carbides.

Thus, investigations showed the high cold cracking resistance of the deposited metal under the condition of welding $15 \mathrm{Kh} 12 \mathrm{VNMFA}$ steel joint with preheating and concurrent heating up to the temperature of $250^{\circ} \mathrm{C}$.

Additional testing for crack resistance with application of rigid joint of Tekken type was used to refine the thermal mode of welding. Tekken technological samples were welded with Thermanit MTS-4 and Kupfer 3KC electrodes without preheating and with preheating at 150,200 and $250{ }^{\circ} \mathrm{C}$. After welding the butt joints were subjected to thermal relaxation soaking in a furnace with $200{ }^{\circ} \mathrm{C}$ temperature. After relaxation, the joints were cooled in still air to room temperature and were stored for $48 \mathrm{~h}$.

Such soaking is required to enable development of delayed fracture in joints susceptible to cracking, and check the guaranteed resistance of welded joint to this kind of fracture. This was followed by examination of the metal of weld and HAZ with a magnifier with three-fold increase and in MBS microscope.

It was found that in welding of technological samples without preheating cold cracks formed in all the cases.

Table 3 gives the results of assessment of technological strength in sample welding with preheating to 150,200 and $250{ }^{\circ} \mathrm{C}$.

Obtained results confirm the need to apply preheating to $200-250{ }^{\circ} \mathrm{C}$ to provide high cold cracking resistance of $15 \mathrm{Kh} 12 \mathrm{VNMFA}$ steel welded joints. Here, the necessary condition to ensure the required thermal mode of welding is achieving cooling rate $\omega_{5 / 3}$ of HAZ metal at the level, not higher than $9{ }^{\circ} \mathrm{C} / \mathrm{s}$.
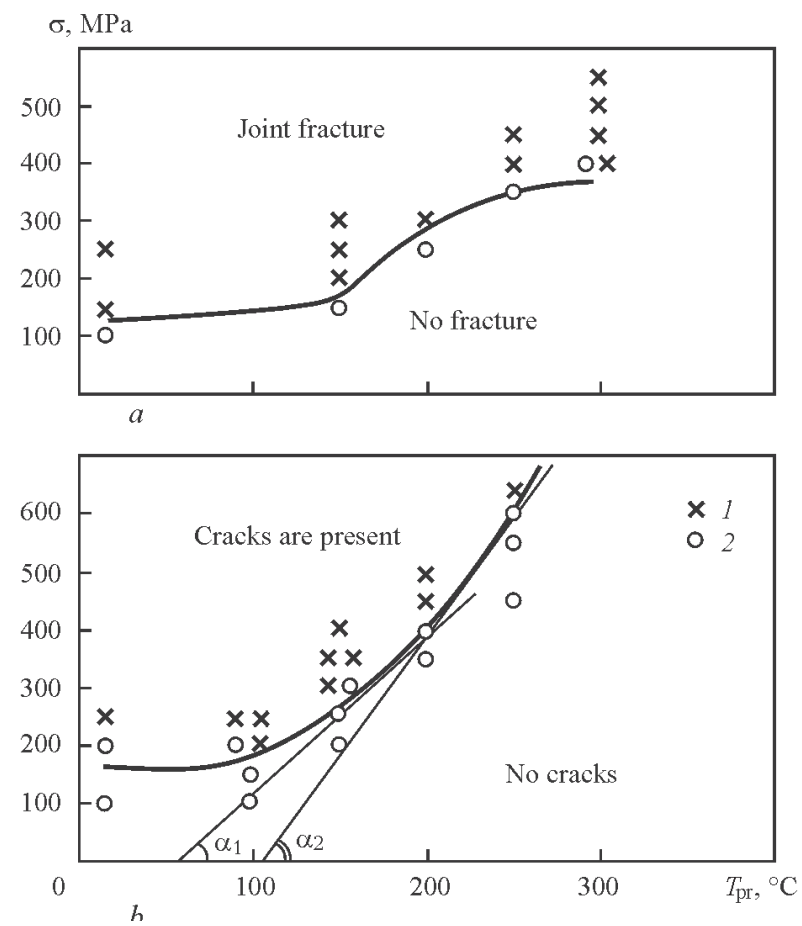

Figure 7. Influence of $15 \mathrm{Kh} 12 \mathrm{VNMFA}$ steel preheating temperature on delayed cracking susceptibility by Implant method testing: $a-$ critical breaking stresses in welding with electrodes MTS-4; $b-$ Kupfer $3 \mathrm{KC}$ electrodes; 1 - test conditions, in which delayed fracture was absent; 2 - conditions, leading to fracture

Investigations showed that at preheating temperature of $150{ }^{\circ} \mathrm{C}$, the weld metal can form cracks. In $\mathrm{HAZ}$ metal cracks are absent. At temperature increase to $200{ }^{\circ} \mathrm{C}$, cracks are absent in all the zones of welded joint. Considering the need to ensure a margin of technological strength at development of steel MAW technology, temperature of preheating and concurrent heating was set at the level of $250^{\circ} \mathrm{C}$.

Thus, proceeding from obtained results, the following approach to welding joints of $15 \mathrm{Kh} 12 \mathrm{VNMF}$ and $15 \mathrm{Kh} 1 \mathrm{M} 1 \mathrm{FL}$ steel can be recommended:

- welding with preheating to $200-250{ }^{\circ} \mathrm{C}$ at mandatory temperature monitoring, to prevent its lowering below $200{ }^{\circ} \mathrm{C}$;

- relaxation after welding at $200{ }^{\circ} \mathrm{C}$ during the time, determined from the ratio of $10 \mathrm{~min} / 1 \mathrm{~mm}$ of weld thickness (determined experimentally from the condition of ensuring cold cracking resistance in a technological sample with about $5 \mathrm{~mm}$ thick weld at soaking at the above temperature for $20 \mathrm{~min}$ );

- joint cooling to the temperature of approximately $150{ }^{\circ} \mathrm{C}$ (for completion of residual austenite decomposition);

Table 3. Influence of preheating temperature on cooling rate of HAZ metal and delayed cracking resistance of Tekken butt samples on $15 \mathrm{Kh} 12 \mathrm{VNMFA}$ steel

\begin{tabular}{|c|c|c|c|}
\hline$T_{\mathrm{pr}}{ }^{\circ} \mathrm{C}$ & 150 & 200 & 250 \\
\hline$\omega_{5 / 3},{ }^{\circ} \mathrm{C} / \mathrm{s}$ & 9.7 & 6.3 & 4.2 \\
\hline Cracks & Present & None & None \\
\hline
\end{tabular}




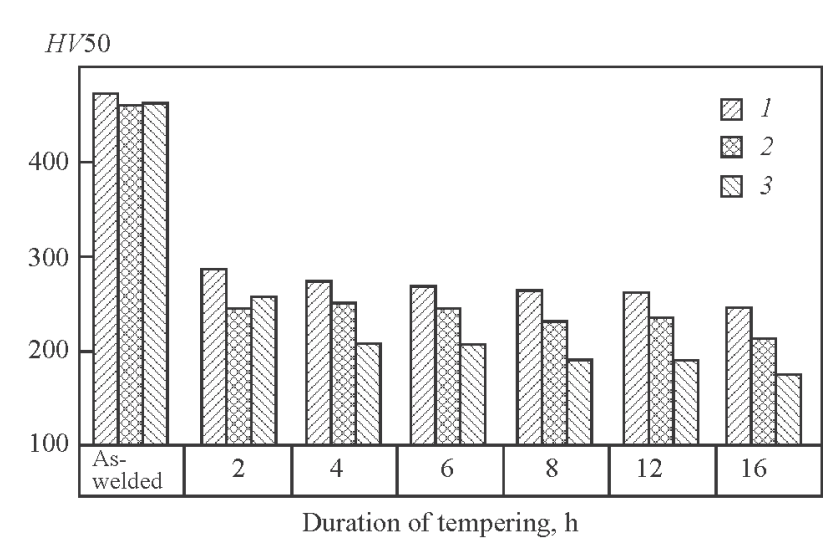

Figure 8. Influence of duration of tempering of combined welded joints on hardness of weld metal and HAZ sections at $0.2-0.5 \mathrm{~mm}$ distance from the fusion line: $1-15 \mathrm{Kh} 12 \mathrm{VNMF}$ steel; $2-$ MTS-4 weld; $3-15 \mathrm{Kh} 1 \mathrm{M} 1 \mathrm{~F}$ steel

- performance of high tempering.

Selection of optimum heat treatment mode is based on the results of measurement of welded joint hardness (in the metal of weld and HAZ) and impact bend testing of weld metal after various tempering modes.

Results of hardness measurement in as-welded and tempered states are given in Figure 8. It is seen that after an abrupt hardness decrease during tempering for $2 \mathrm{~h}$, further soaking leads to gradual lowering of hardness values for all the joint zones. Hardness starts decreasing more abruptly after more than $12 \mathrm{~h}$ soaking. Here, after tempering for $16 \mathrm{~h}$ hardness of HAZ metal in $15 \mathrm{Kh} 1 \mathrm{M} 1 \mathrm{~F}$ steel reaches $H V 173$ (that corresponds to about $H B$ 163), in steel with $12 \% \mathrm{Cr}-H V 246$ (or about $H B$ 235). In all the tempering modes, weld hardness takes up an intermediate position. After $16 \mathrm{~h}$ tempering, the weld has $H V 215$ (HB 204).
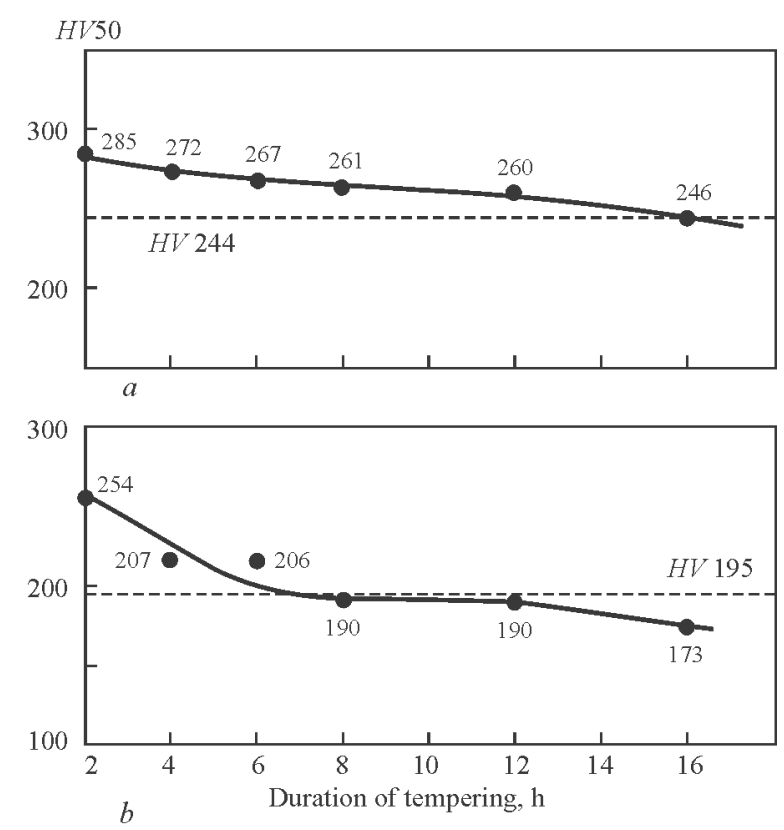

Figure 9. HAZ metal hardness at welded joint tempering at $720{ }^{\circ} \mathrm{C}$, compared with initial hardness of steel: $a-15 \mathrm{Kh}-$ 12VNMF steel HAZ; $b-15 \mathrm{Kh} 1 \mathrm{M} 1 \mathrm{~F}$
During heat treatment, it is important to prevent deterioration of mechanical properties of base metal and metal in welded joint zone. In this case, such a characteristic can be strength, proportional to hardness value. As is seen from Figure 9, $a$, hardness of HAZ metal in 15Kh12VNMF steel drops below that of steel in the initial state (dashed line on the level of $H V$ 244) after tempering at $720^{\circ} \mathrm{C}$ of more than $16 \mathrm{~h}$ duration. HAZ metal hardness from the side of $15 \mathrm{Kh} 1 \mathrm{M} 1 \mathrm{~F}$ steel (Figure 9, $b$ ) drops below that of initial steel after soaking for 8-12 h.

Therefore, tempering for more than $8 \mathrm{~h}$ leads to softening of welded joints (both HAZ and, probably, base metal) in the region of $15 \mathrm{Kh} 1 \mathrm{M} 1 \mathrm{~F}$ steel. In $15 \mathrm{Kh} 12 \mathrm{VNMF}$ steel such softening occurs at tempering for more than $16 \mathrm{~h}$.

Results of hardness measurement lead to the conclusion that tempering duration should be not more than $8 \mathrm{~h}$.

Results of checking the influence of tempering mode on impact toughness $K C V$ of weld metal are given in Figure 10. The above data shows that the welds had quite high $K C V$ values after all soaking at $720^{\circ} \mathrm{C}$. Thus, the following mode can be recommended for tempering the studied combined joints: temperature of $720^{\circ} \mathrm{C}$, duration of $8 \mathrm{~h}$.

Testing for static tension was performed on transverse samples from the welded joint and longitudinal samples of weld metal. Impact bend testing was performed using transverse samples with a sharp notch in the weld (type IX, GOST 6996-66). Testing was conducted at room $\left(20^{\circ} \mathrm{C}\right)$ and at working $\left(570{ }^{\circ} \mathrm{C}\right)$ temperatures. Samples of type II were used for static tension tests at $20^{\circ} \mathrm{C}$, and samples of type IV to GOST 6996-66 were applied at $570{ }^{\circ} \mathrm{C}$.

Test results are given in Table 4.

In all the cases, at static tension tests of transverse samples fracture proceeded through HAZ metal of one of the steels being welded, depending on testing temperature. At $T_{\text {test }}=20^{\circ} \mathrm{C}$, fracture ran through $15 \mathrm{Kh} 1 \mathrm{M} 1 \mathrm{~F}$ steel, at $570{ }^{\circ} \mathrm{C}$ it ran through $15 \mathrm{Kh}$ 12 VNMF steel.

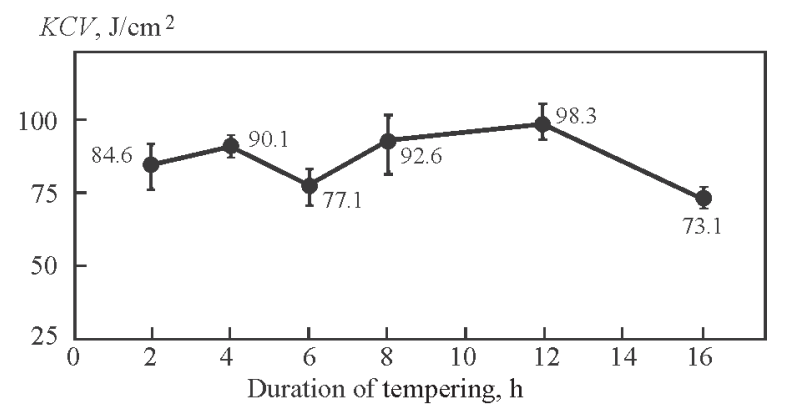

Figure 10. Influence of long-term tempering at $720{ }^{\circ} \mathrm{C}$ on $\mathrm{KCV}$ of weld metal in joints of $15 \mathrm{Kh} 1 \mathrm{M} 1 \mathrm{~F}$ and $15 \mathrm{Kh} 12 \mathrm{VNMF}$ steel welded with Thermanit MTS-4 electrodes 
Table 4. Mechanical properties of joints of $15 \mathrm{Kh} 1 \mathrm{M} 1 \mathrm{~F}+15 \mathrm{Kh} 12 \mathrm{VNMF}$ type welded with Thermanit MTS-4 electrodes (tempering at $720^{\circ} \mathrm{C}, 8 \mathrm{~h}$ ) with fracture through $\mathrm{HAZ}$

\begin{tabular}{|c|c|c|c|c|c|c|c|}
\hline \multirow{2}{*}{$T_{\text {test }},{ }^{\circ} \mathrm{C}$} & $\sigma_{0.2}, \mathrm{MPa}$ & $\sigma_{\mathrm{t}}, \mathrm{MPa}$ & $\delta, \%$ & $\psi, \%$ & $K C V, \mathrm{~J} / \mathrm{cm}^{2}$ & $\sigma_{t}, \mathrm{MPa}$ & $\psi, \%$ \\
\hline & \multicolumn{5}{|c|}{ Weld metal } & \multicolumn{2}{|c|}{ Welded joint } \\
\hline 20 & $553.8-557.7$ & $690.7-717.7$ & $22.75^{*}$ & $55.0-57.9$ & 93 & $554.2-569.1$ & $48.6-57.6$ \\
\hline 570 & $317.6-321.7$ & $381.6-395.0$ & $29.2-30.3$ & $80.7-84.3$ & $184.3-195.5$ & $371.6-379.7$ & $67.0-68.8$ \\
\hline
\end{tabular}

Microstructural features in as-welded condition and after earlier established optimum tempering at $720{ }^{\circ} \mathrm{C}$ for $8 \mathrm{~h}$ were studied. Revealing the microstructure on polished sections was performed by twostage etching:

- chemical, in 3\% alcohol solution of nitric acid;

- electrochemical, in chromic acid at voltage of $8 \mathrm{~V}$ for $20 \mathrm{~s}$.

First etching was used to identify the structure in low-alloyed steel, the second one - in the weld and high-alloyed steel.

The following structural features of base metal and welded joints were revealed.

First of all, it should be noted that microstructures of welded joint, particularly, HAZ metal, are characterized by non-uniform structure. Microinhomogeneity is more pronounced in the HAZ metal of $15 \mathrm{Kh} 1 \mathrm{M} 1 \mathrm{~F}$ steel. Here, microregions of different etching intensity and different colouring form, because of the possibility of formation of a number of austenite transformation products and their partial modification under the impact of thermodeformational cycles in multipass welding.

A feature of HAZ metal structure in $15 \mathrm{Kh} 1 \mathrm{M} 1 \mathrm{~F}$ steel after high tempering is appearance of $\alpha$-ferrite regions located along the boundary with the weld. Regions in the form of interlayers, consisting just of ferrite, and regions of mixed structure in the form of ferrite grains and products of tempering of initial acicular quenching structure are observed. Ferrite interlayer has different width at different levels of the joint cross-section, varying approximately from 0.7 to $1.4 \mathrm{~mm}$. A carbide interlayer (ridge) formed in the weld along the weld-HAZ interface, which acquired a dark colour after etching.

Development of structural inhomogeneity along the HAZ-weld boundary is the consequence of diffusion redistribution of carbon, caused by the difference in the content of carbide-forming elements in the base metal and weld. In this joint, the difference in chromium alloying of low-alloyed steel and high-alloyed weld had a decisive influence on development of non-uniform carbon distribution. Carbon tends to accumulate in the region of greater chromium content. In this case, depletion of carbon in the regions adjacent to the weld led to appearance of $\alpha$-ferrite, and its accumulation in the weld - to increased carbide concentration. Such structural inhomogeneity is characteristic for combined joints and can form both in welding and in tempering. On the whole, it does not seem possible to prevent its appearance without changing weld alloying or welding technology.

HAZ metal structure of chromium high-alloyed steel after tempering of initial martensite is a ferrite-carbide mixture, formed as a result of carbide precipitation along the boundaries of primary austenite grains and along the sub-boundaries inside the grains. In addition to martensite tempering products, individual grains of $\delta$-ferrite, initially present in the base metal, are observed in the HAZ metal structure.

It is found that the studied steel HAZ has a region of lower hardness. It can be assumed that fracture of tensile samples at testing at $570{ }^{\circ} \mathrm{C}$ ran exactly through this softening zone.

Metallographic examination of metal microstructure in the fracture zone was additionally performed. The metal failed at development of plastic flow, that was seen in the arrangement of rows of disperse intragranular precipitates along the deformation directions. In the locations, where tempered martensite structure contained $\delta$-ferrite, fracture ran along $\delta$-ferrite-martensite interphases; no fractures were found in the ferrite phase.

Thus, it can be assumed that lowering of HAZ metal strength in $15 \mathrm{Kh} 12 \mathrm{VNMF}$ steel can be related to fine structural changes and to additional tempering, due to the impact of welding heating.

Structure of weld of Thermanit MTS-4 type with high chromium content, similar to $15 \mathrm{Kh} 12 \mathrm{VNMF}$ steel, after initial martensite tempering, is a uniform finely dispersed ferrite-carbide mixture. Weld hardness varies approximately from $H V 250$ near the low-alloyed steel edge to $H V 290$ at high-chromium steel.

Proceeding from the conducted investigations, the main principles of basic technology of welding and heat treatment of combined joints of $15 \mathrm{Kh} 1 \mathrm{M} 1 \mathrm{FL}$ steel with 15Kh12VNMFA steel were developed.

To finalize selection of electrode grades for welding the load-carrying welds, samples of welded joints of $15 \mathrm{Kh} 1 \mathrm{M} 1 \mathrm{FL}$ steel with $15 \mathrm{Kh} 12 \mathrm{VNMFA}$ steel, made with Thermanit MTS-4 and Phoenix SH Kupfer 
$3 \mathrm{KC}$ electrodes, were prepared for long-term strength and creep testing at $570{ }^{\circ} \mathrm{C}$. These test results will be used to take an engineering decision on selection and application of electrodes for welding standard items.

\section{Conclusions}

1. Diaphragm is one of the most critical components of steam turbine flow section, responsible for ensuring the reliability and performance of the turbine unit and TPP power unit as a whole.

2. Currently available technology of welding the high-temperature diaphragms of HPC and MPC does not provide operational reliability of the flow section of powerful steam turbines, contributes to shortening of operating life and leads to emergency situations at TPP.

3. Features of operational damage in high-temperature diaphragm welded components were studied. It is shown that the main damage in long-term operation forms in welded joints of guide vanes with the diaphragm body and rim. Fracture runs through the zone of fusion of guide vane end face with weld metal.
4. To increase the operational efficiency and reliability of high-temperature diaphragms, new consumables were selected for welding load-carrying welds, and main principles of basic technology of welding and heat treatment were developed, providing high quality and required performance of combined joints.

1. Shlyakhin, P.N. (1974) Steam and gas turbines. Moscow: Energiya.

2. OST 108.021.04-78: Stationary steam turbines. Welded diaphragms, guide apparatuses. General specifications. Introd. 01.01.79.

3. Mellerovich, G.M., Pelipenko, E.N., Pokrassa, M.I. et al. (1969) Study of stress state of steam turbine casings and diaphragms. Problemy Prochnosti, 4, 19-22.

4. (1978) Stresses and strains in steam turbine parts. Kiev: Naukova Dumka.

5. Kulagina, G.F. (1960) Experimental study of stresses and deflections of diaphragms. In: Study of steam and gas turbines and axial compressors, 333-346. Moscow: Mashgiz.

6. TI-656-2007: Welded diaphragms, preparation for welding, welding, heat treatment and quality control. Kharkov: Turboatom.

7. RTM 108.020.35-81: Stationary steam turbines. Welding and heat treatment of diaphragms and guide apparatuses. Fundamentals.

8. Kozlov, R.A. (1986) Welding of heat-resistant steels. Leningrad: Mashinostroenie.

Received 22.12.2015 